\title{
Feasibility of backfilling mines using cement kiln dust, fly ash, and cement blends
}

\author{
H. Beltagui ${ }^{1,2}$, M. Sonebi ${ }^{1}$, K. Maguire ${ }^{2}$, and S. Taylor ${ }^{1}$ \\ ${ }^{1}$ School of Natural and Built Environment, Queen's University Belfast, Belfast, Co. Antrim, BT7 1NN, UK \\ ${ }^{2}$ Quinn Building Products, Derrylin, Co. Fermanagh, BT92 9GP, UK
}

\begin{abstract}
Cement kiln dust (CKD) is an industrial by-product of the cement manufacturing process, the composition of which can vary widely. Recent years of using alternative fuels have resulted in higher chloride and alkali contents within CKDs; as such, this limits the applications in which CKDs can be utilised. Using a CKD containing a high free lime content of $29.5 \%$, it is shown that this CKD is capable of activating pulverized fuel ash (PFA) due to its high alkalinity, which can be utilised in low strength un-reinforced applications. One potential application involves the backfill of mines, reducing the need for continuous maintenance of the mine. This study focuses on the compressive strength achieved by various blends of CKD, PFA, and cement. Samples were hand mixed and compacted in $100 \mathrm{~mm}$ x $50 \mathrm{~mm}$ diameter cylinders, and unconfined compressive strength measurements taken at 28 and 56 days. The hydration products were assessed through the use of $\mathrm{x}$-ray diffraction and thermogravimetric analysis. Aiming to maximise the use of CKD at a water to binder (w/b) ratio of 0.2 , it was found that the maximum CKD content possible to achieve the required strength was $90 \%$ CKD blended with $10 \%$ cement.
\end{abstract}

\section{Introduction}

Cement kiln dust (CKD) is an industrial by-product of the cement manufacturing process, the composition of which can vary widely. Due to the generation of large quantities, it is important both from an environmental and economic view to find suitable applications for this material. Traditionally, a portion of the CKD produced can be returned to the cement production process. However, recent years of using alternative fuels, such as solid recovered fuel (SRF), have resulted in higher chloride and alkali contents within CKDs.

The high alkalinity of these CKDs can be exploited by blending with alkali activated materials, such as pulverised fly ash (PFA) or slags. Typically, Portland cement is also blended to provide high early strength, while the alkali activation can improve the long term strength and durability of the concrete. It has previously been shown that additions of up to $10-15 \%$ CKD by weight to high volume fly ash and slag concretes can produce improved strengths to blends with no added CKD $[1,2]$.

The potential for CKDs to activate materials such as PFA and slags typically lies in the form which the calcium oxide takes. While free-lime $(\mathrm{CaO})$ and calcium hydroxide $\left(\mathrm{Ca}(\mathrm{OH})_{2}\right)$ typically have the capacity for activation, calcium carbonate $\left(\mathrm{CaCO}_{3}\right)$ is inert and therefore unreactive.

However, the use of such CKDs in reinforced concrete applications is not possible as the chlorides present a high risk of corrosion to the reinforcement. Moreover, the alkalis may result in alkali-silica reactions (ASR) between the pore fluid and the aggregates to take place, causing expansion and cracking of the concrete. Therefore, alternative applications require investigation where the chlorides and alkalis do not present any durability issues.

One potential application for harnessing the alkali activation potential of these blends involves the backfill of mines, reducing the need for continuous maintenance and to extend the life of the mine. While there are several different types of filling techniques used in the mining industry, hydraulic fills using blends of cement and PFA have been used in the past. The blends can be mixed either below or above ground, and pumped into the mine. Typical strength requirements of the material used can be as low as $3 \mathrm{MPa}$ at 56 days, with the chemical composition of the fill material not being of concern, making it an ideal application for the utilisation of such CKDs. Moreover, it can be a cost effective solution for the backfilling of mines. 
This study focuses on the compressive strength achieved by various blends of CKD, PFA, and cement. The unconfined compressive strength was measured, and the failure modes recorded. In conjunction, the hydration products were investigated, providing an understanding for the differences in the strengths achieved.

\section{Materials and methods}

\subsection{Materials}

The chemical oxide compositions of the CKD, PFA, and cement used, as measured by XRF, are shown in Table 1. The CKD used had a high chloride content of $11.68 \%$, making it unsuitable for many applications, and almost $50 \%$ of the CKD was composed of $\mathrm{CaO}$.

Table 1. Oxide composition of materials

\begin{tabular}{|c|c|c|c|}
\hline Constituent & CKD (\%) & PFA (\%) & $\begin{array}{c}\text { CEM I } \\
(\%)\end{array}$ \\
\hline $\mathrm{CO}_{2}$ & 1.27 & 5.40 & \\
\hline Water & 1.06 & & \\
\hline LOI & 2.33 & 5.40 & 3.00 \\
\hline $\mathrm{SiO}_{2}$ & 8.16 & 51.77 & 19.83 \\
\hline $\mathrm{Al}_{2} \mathrm{O}_{3}$ & 3.68 & 21.54 & 4.80 \\
\hline $\mathrm{TiO}_{2}$ & 0.12 & 0.94 & \\
\hline $\mathrm{P}_{2} \mathrm{O}_{5}$ & 0.12 & 0.68 & \\
\hline $\mathrm{Fe}_{2} \mathrm{O}_{3}$ & 1.62 & 6.28 & 3.02 \\
\hline $\mathrm{MgO}$ & 1.46 & 2.06 & \\
\hline $\mathrm{CaO}$ & 47.98 & 5.53 & 63.06 \\
\hline $\mathrm{SO}_{3}$ & 7.04 & 0.84 & 2.48 \\
\hline $\mathrm{Na}_{2} \mathrm{O}$ & 3.62 & 2.55 & \\
\hline $\mathrm{K}_{2} \mathrm{O}$ & 14.64 & 2.40 & \\
\hline $\mathrm{Cl}^{-}$ & 11.68 & & \\
\hline
\end{tabular}

To assess the reactivity of the CKD, the material was analysed by X-ray diffraction (XRD) Rietveld, using the external G-factor method [3], and the resulting mineralogical composition shown in Table 2. It was identified that the main phases present in the CKD were free-lime, sylvite, and belite. Due to the availability of the $\mathrm{CaO}$ mainly as free-lime, rather than calcium carbonate, the activation of the PFA becomes possible.

The main crystalline phases of the PFA were identified to be quartz and mullite, both of which are considered unreactive. The reactivity potential of the PFA lies within the amorphous content, which is likely to be composed mainly of aluminosilicate glasses. As quantified by XRDRietveld, the amorphous content of the PFA was found to be $73.9 \%$. To ensure consistency between samples, the PFA was dried at $105^{\circ} \mathrm{C}$ prior to use, while the CKD and cement were used as received.

Table 2. Mineralogical phase composition of CKD

\begin{tabular}{|c|c|c|}
\hline $\begin{array}{c}\text { Mineralogical } \\
\text { phase }\end{array}$ & $\begin{array}{c}\text { Chemical } \\
\text { composition }\end{array}$ & $\begin{array}{c}\text { Phase content } \\
(\%)\end{array}$ \\
\hline Free lime & $\mathrm{CaO}$ & 29.5 \\
\hline Sylvite & $\mathrm{KCl}$ & 21.4 \\
\hline Belite & $\mathrm{Ca}_{2} \mathrm{SiO}_{4}$ & 17.5 \\
\hline Dolomite & $\mathrm{CaMg}\left(\mathrm{CO}_{3}\right)_{2}$ & 6.0 \\
\hline Portlandite & $\mathrm{Ca}(\mathrm{OH})_{2}$ & 3.8 \\
\hline Anhydrite & $\mathrm{CaSO}$ & 3.7 \\
\hline Arcanite & $\mathrm{K}_{2} \mathrm{SO}_{4}$ & 8.4 \\
\hline Ferrite & $\mathrm{Ca}\left(\mathrm{Al}_{2}, \mathrm{Fe}_{2} \mathrm{O}_{5}\right.$ & 5.2 \\
\hline Quartz & $\mathrm{SiO}_{2}$ & 3.1 \\
\hline Syngenite & $\mathrm{K}_{2} \mathrm{Ca}\left(\mathrm{SO}_{4}\right)_{2} \cdot \mathrm{H}_{2} \mathrm{O}$ & 1.3 \\
\hline
\end{tabular}

\subsection{Methods}

The mix designs were selected based on maximising the use of CKD in the mix, with the used mix designs shown in Table 3. In order to achieve sufficient compaction, a dry mix was preferred; as such, a w/b ratio of 0.2 was selected to be used for all mixes. However, two of the mix designs (mixes $\mathrm{C}$ and $\mathrm{J}$ ) were tested at varying $\mathrm{w} / \mathrm{b}$ ratios, up to a $\mathrm{w} / \mathrm{b}$ ratio of 0.4 , to investigate the effects of moisture content on the compressive strength.

Table 3. Mix designs

\begin{tabular}{|c|c|c|c|}
\hline Mix Design & PFA & CKD & CEM I \\
\hline A & 90 & 10 & \\
\hline B & 80 & 20 & \\
\hline C & 70 & 30 & \\
\hline D & 60 & 40 & \\
\hline E & 50 & 50 & \\
\hline F & 60 & 38 & 2 \\
\hline G & 50 & 47.5 & 2.5 \\
\hline H & 60 & 36 & 4 \\
\hline I & 50 & 45 & 5 \\
\hline J & & 95 & 5 \\
\hline K & & 90 & 10 \\
\hline L & & 80 & 20 \\
\hline M & & 70 & 30 \\
\hline
\end{tabular}

The samples were prepared by firstly blending the dry materials, and then hand mixing in a tray with the water added. Following this, the mixes were then passed through a sieve with a $5 \mathrm{~mm}$ mesh size to ensure that the 
compaction was not affected by particle size. As the water added was very little, the material remained somewhat dry as shown in Figure 1a.
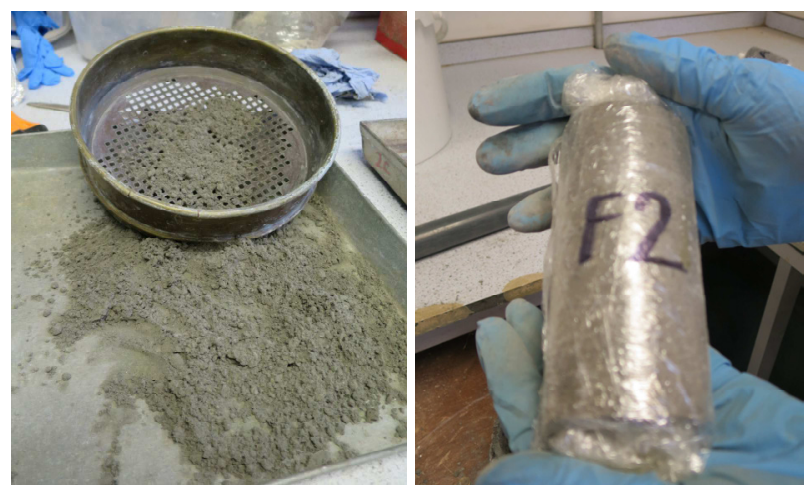

Fig. 1. (a) dry mix used for sample preparation, and (b) sample wrapped in cling film for storage

The material was then compacted in seven layers into a $100 \mathrm{~mm}$ by $50 \mathrm{~mm}$ diameter cylindrical mould. After demoulding immediately, each sample was wrapped in cling film to prevent any loss of moisture during curing, as shown in Figure 1b. At the specified test age of 56 days, the unconfined uniaxial compressive strength was measured at a displacement rate of $1 \mathrm{~mm} / \mathrm{min}$. Each strength measurement represents the average strength measured of 3 replicate samples.

To understand the effects of the mineralogy on the compressive strength, the hydrated phases of four of the mix designs were analysed at 56 days by XRD and thermogravimetric analysis (TGA). These samples were prepared with a higher $w / b$ ratio of 0.35 , and were ground to a powder and tested immediately without any ceasing of hydration to prevent any damage to crystalline structures. XRD data were collected using a PANAlytical XPert Powder diffractometer in the Bragg-Brentano geometry with tube operating conditions of $45 \mathrm{kV}$ and 40 $\mathrm{mA}$, and $\mathrm{CuK} \alpha$ radiation with a beam wavelength of 1.5418 Á. Thermogravimetric analysis (TGA) was used in combination to identify any amorphous phases within the samples, using a TG 209 F1 Libra, with the sample placed in a flowing nitrogen atmosphere from $20^{\circ} \mathrm{C}$ to $950^{\circ} \mathrm{C}$, and a heating rate of $20 \mathrm{C} / \mathrm{min}$.

\section{Results and discussion}

\subsection{Unconfined compressive strength}

The unconfined compressive strength of the PFA and CKD blends (mixes A-E) with a w/b ratio of 0.2 at 56 days are shown in Figure 3. It is evident that all samples surpassed the required $3 \mathrm{MPa}$ with very little variation, reaching strengths of between 4.7 and 5.6 $\mathrm{MPa}$, except mix design A which only gained $2.14 \mathrm{MPa}$. It is likely that in mix A the CKD content was insufficient to activate the PFA.

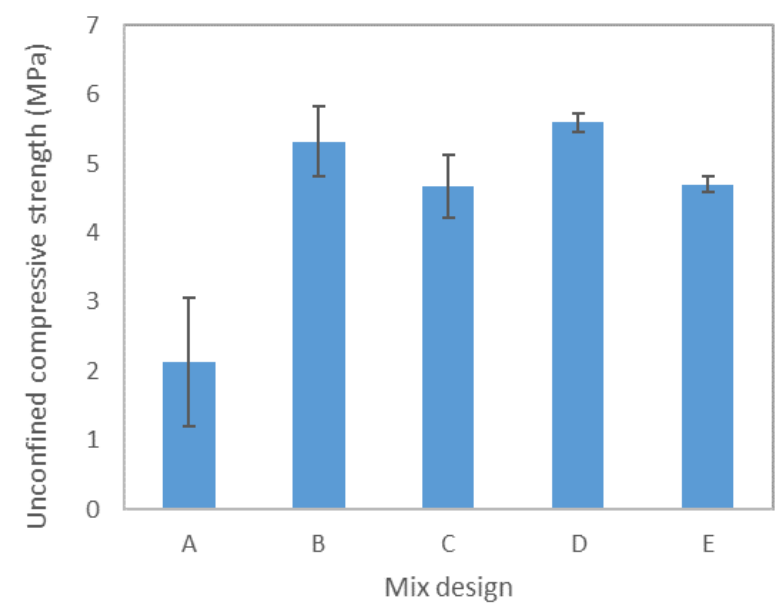

Fig. 3. Compressive strength of PFA and CKD blends with a w/b ratio of 0.2 at 56 days

Figure 4 illustrates the unconfined compressive strength of mixes F - I, which are composed of PFA, CKD, and cement. It is apparent that the addition of small amounts of cement to the mixes did not improve the strength; in fact, a slight drop in the strength was observed. This drop in the strength is likely due to a lack of water availability to fully hydrate the cement, resulting in inert material remaining in the mixes.

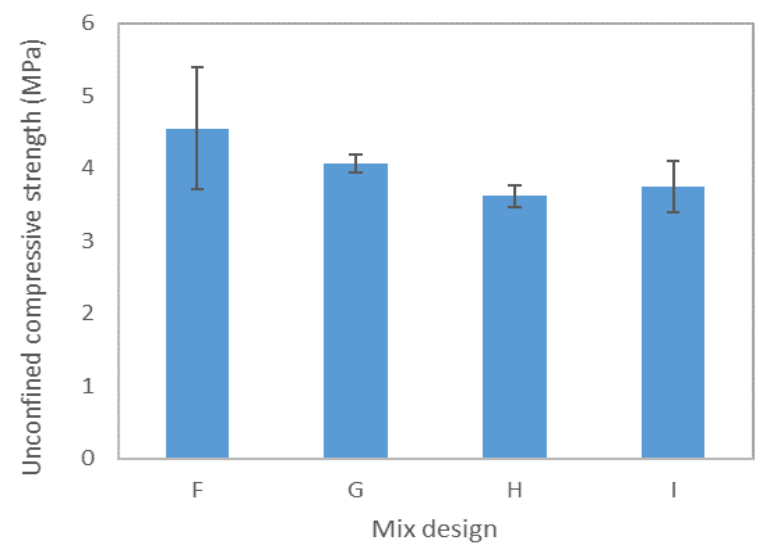

Fig. 4. Compressive strength of PFA, CKD, and cement blends with a w/b ratio of 0.2 at 56 days

In the aim of maximizing the CKD content, CKD and cement only blends were investigated, with the unconfined compressive strengths shown in Figure 5. When blending 95\% CKD and only 5\% cement, a strength of $2.8 \mathrm{MPa}$ was achieved, which was insufficient to meet the strength requirement of $3 \mathrm{MPa}$. However, samples with greater than $5 \%$ cement surpassed the strength requirement, reaching strengths of up to $5.2 \mathrm{MPa}$ when $30 \%$ cement was blended. However, additions of these levels of cement in the blends are unlikely to be economic in the current application. 


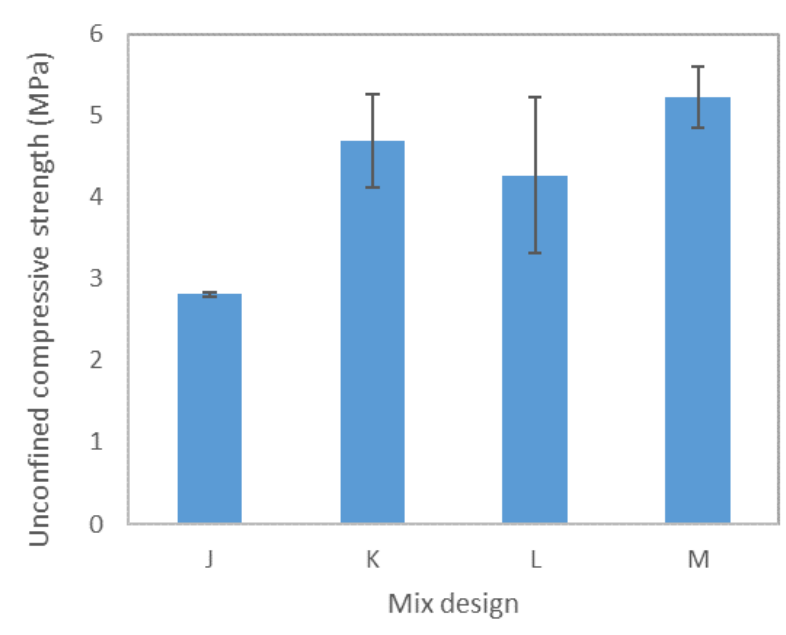

Fig. 5. Compressive strength of CKD and cement blends with a w/b ratio of 0.2 at 56 days

Two of the mix designs, mix $\mathrm{C}$ and mix $\mathrm{J}$, were selected to be used for investigating the impact of the w/b ratio on the unconfined compressive strength. Figure 6 illustrates an improvement in the strengths when higher $\mathrm{w} / \mathrm{b}$ ratios are used. This is more apparent in the mix design containing PFA, where the increased water would result in greater activation of the aluminosilicates in the PFA. On the other hand, increased w/b ratio had less of an impact on the mix design containing cement. As the $w / b$ increases in this mix, it is likely that much of it is uptaken by the free-lime in the CKD, leaving little to fully hydrate the cement in the mix. However, in both cases, it is evident that the water content played a role in the strengths achieved.

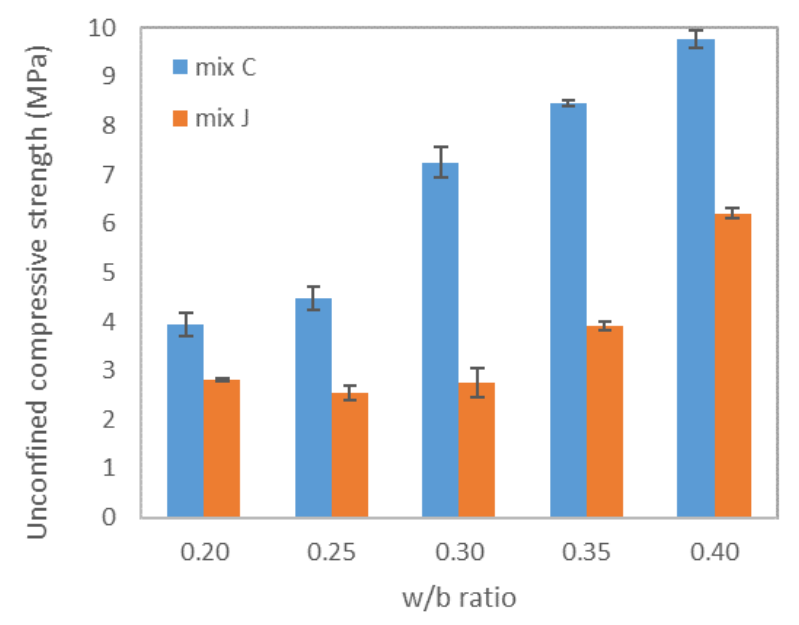

Fig. 6. Compressive strength of mix $\mathrm{C}$ and mix $\mathrm{J}$ varying w/b ratio at 56 days

\subsection{Hydration products}

To investigate the activation potential of the CKD, and the further understand the strengths achieved, the hydration products were investigated on four of the mix designs containing CKD and PFA at 56 days, with the XRD patterns shown in Figure 7. The broad "hump" between $\sim 15^{\circ}$ and $\sim 35^{\circ} 2 \theta$, which is associated with the amorphous content is most apparent in mix $\mathrm{B}$, and appears to reduce with increasing CKD content. This is likely a result of two factors: (i) the reduction in the PFA content reduces the final amorphous content of the mix, and (ii) increasing the CKD content provides conditions for higher activation and reactivity of the PFA.

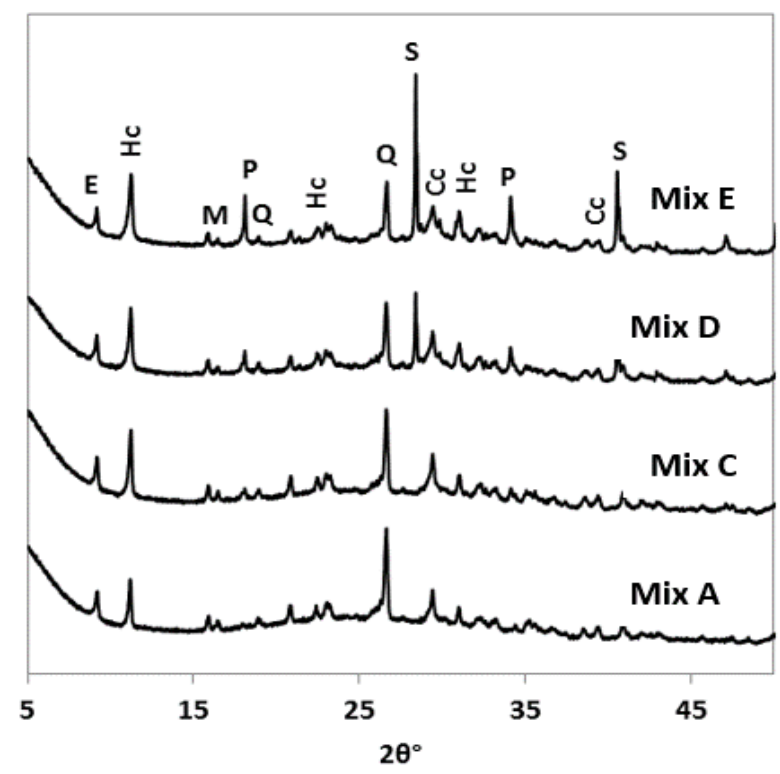

Fig. 7. XRD patterns of hydrated PFA and CKD blends at 56 days, where $\mathrm{E}=$ Ettringite, $\mathrm{Hc}=$ Hemi-carbonate, $\mathrm{M}=$ Mullite, $\mathrm{P}=$ Portlandite, $\mathrm{Q}=$ Quartz, $\mathrm{S}=$ Sylvite, and $\mathrm{Cc}=$ Calcium carbonate.

At 56 days, the free-lime contained within the CKD was fully consumed in all cases. Upon initial contact with the mixing water, the free-lime is rapidly converted to calcium hydroxide (Portlandite). Increasing the CKD content results in higher calcium hydroxide formation and higher alkalinity of the pore solution; this provides suitable conditions for the pozzolanic reaction with the aluminosilicate glasses in the PFA to form C-S-H phases. The unconfined compressive strength results were in agreement with this, whereby higher strengths were achieved in the higher CKD content blends with PFA.

However, the XRD patterns show that the amount of residual calcium hydroxide at 56 days increases as the CKD content increased. This suggests that the calcium hydroxide exceeded the amount required to react with the PFA at 56 days. It is possible that the pozzolanic reaction of the PFA will continue to progress slowly with further curing time. On the other hand, the reduction in the strength with the addition of CKD past $40 \%$ suggests rather that the optimum CKD for reaction with the PFA has been surpassed; it is likely that the total pozzolanic reaction is close to its full potential. 
Unreactive quartz and mullite remained present in all samples at 56 days. While sylvite was almost completely absent from the samples containing only 20 and $30 \% \mathrm{CKD}$, the residual sylvite content at 56 days increased with further CKD addition. At the lower CKD contents, uptake of the small amounts of potassium and chloride ions present into the $\mathrm{C}-\mathrm{S}-\mathrm{H}$ structure may have been possible.

The main crystalline product of CKD-PFA blends has been previously been observed to be ettringite [4], which was also formed in all samples in the present study. Ettringite formation occurs due to reaction of the sulfate bearing phases, anhydrite and arcanite, with the alumina from ferrite or the PFA. Ettringite is known to contribute to strength gain as it has a lower density (1.78 $\mathrm{g} \mathrm{cm}^{-3}$ ) than many other hydrates in cements, and is suggested to have good space filling properties due to the dense packing of its characteristic needle-like crystals [5].

In addition to this, XRD showed the precipitation of hemi-carboaluminate and calcium carbonate in all samples, the carbonate being provided from the PFA.

The TGA-DTG results, shown in Figure 8, confirmed the presence of ettringite and calcium hydroxide, in addition to the formation of amorphous aluminium hydroxide $\left(\mathrm{AH}_{3}\right)$ gel. As the CKD content in the binder increased, the aluminium hydroxide gel was observed to increase due to increased dissolution of the aluminosilicates in the PFA.

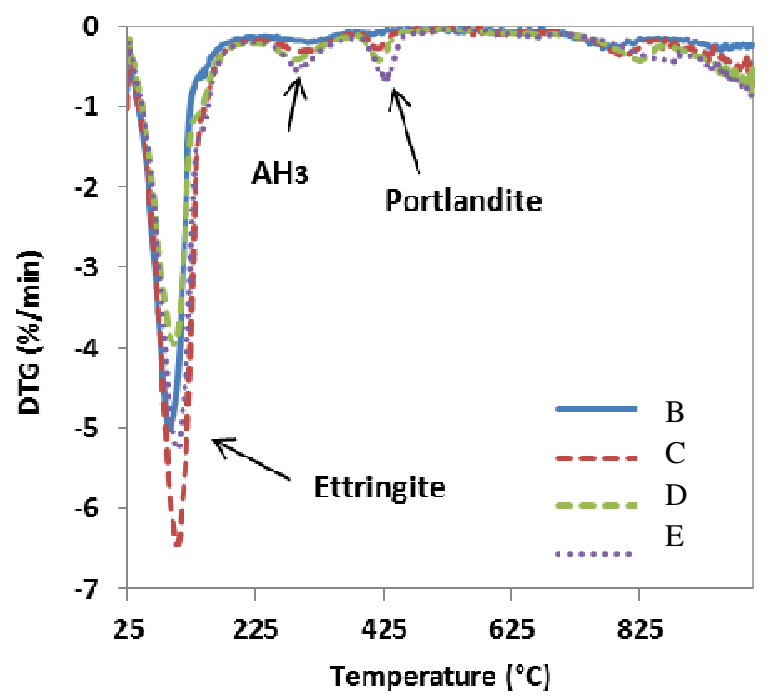

Fig. 8. DTG plots of hydrated PFA and CKD blends at 56 days

The presence of C-S-H could not be directly identified in the DTG plots as the dehydration of this phase typically occurs within the same range of temperatures as ettringite and continues to loss mass across a wide range of temperatures. However, the floating baseline in the DTG plot, and the lack of any crystalline silicate bearing phases in the XRD patterns, suggested that amorphous $\mathrm{C}-\mathrm{S}-\mathrm{H}$ had formed.

\section{Conclusions}

The present study showed that CKD, containing high free-lime content, has the potential to activate the pozzolanic reaction of PFA and provide sufficient mechanical properties for low strength applications. The main hydration products were identified to be ettringite, calcium carbonate, hemi-carboaluminate, portlandite, and amorphous C-S-H and aluminium hydroxide.

Aiming to maximise the use of $\mathrm{CKD}$ at a water to binder $(w / b)$ ratio of 0.2 , it was found that the maximum CKD content possible to achieve the required strength was $90 \%$ CKD blended with $10 \%$ cement. However, it is unlikely to be economic to use cement levels this high, when similar strength can be achieved using only CKD and PFA. On the other hand, when aiming to maximise the strength gained, this was achieved upon increasing the $\mathrm{w} / \mathrm{b}$ ratio to 0.35 , which corresponded to the maximum dry density of the material.

Overall, the results confirm the suitability of using CKD as a backfill material for underground mines. However, some practical considerations should be made regarding its use. Firstly, the high water demand of the mixes due to the free-lime in the CKD, which absorbs water rapidly, produces a large amount of heat which may be difficult to work with in large quantities. In addition to this, the fineness of the material makes it difficult to deal with below the surface in the mines. To deal with this, the mix could be prepared above ground and pumped below, which would require much initial investment. Alternatively, the CKD material can be pretreated with moisture prior to bringing below ground.

Further work will aim to investigate the microstructure of the hydrated pastes, and to quantify the hydrates formed over time to understand the hydration kinetics of these binders. Moreover, taking into account the practical considerations, early trials on site to investigate the use of the material for the backfill of mines will be carried out.

\section{Acknowledgements}

The authors wish to acknowledge the Knowledge Transfer Partnership (KTP) 010446 between Quinn Building Products Ltd and Queen's University Belfast.

\section{References}

1. D. Bondar, E. Coakley, Construction and Building Mat., 71 (2014).

2. M. Sadique, E. Coakley, Adv. Cem. Res. 28 (2016).

3. D. Jansen, Cem. Conc. Res. 41 (2011).

4. K. Wang, S.P. Shah, A. Mishulovich, Cem. Conc. Res. 34 (2004).

5. F.P. Glasser, L. Zhang, Cem. Conc. Res. 31 (2001). 